\title{
Different Fertilization Systems in the Petrova Ecosystem, Maramureş County. Note 1: The Evolution of Forage Production
}

\author{
Doru CRISTE ${ }^{1)}$, Gheorghe MIHAI ${ }^{1)}$, Nicuşor SIMA ${ }^{1)^{*}}$, Adela BOTIŞ ${ }^{1)}$, Iulia MEDREA ${ }^{1)}$, Bogdan FĂGĂDAR ${ }^{1)}$ \\ 1)Faculty of Animal Husbandry and Biotechnologies, University of Agricultural Sciences and Veterinary \\ Medicine, 3-5 Mănăştur Street, 400372, Cluj-Napoca, Romania \\ *Corresponding author, e-mail: flaviusima@yahoo.com
}

Bulletin UASVM Animal Science and Biotechnologies 72(2) / 2015

Print ISSN 1843-5262; Electronic ISSN 1843-536X

DOI:10.15835/buasvmcn-asb:11485

\begin{abstract}
Set on a Festuca rubra - Agrostis capillaris (Agrostis tenuis) grassland, at a height of $628 \mathrm{~m}$ in the Maramureș Depression, the experiment was carried out by means of the randomized blocks method. We performed a bifactorial experiment with factor A as the amendment, and factor B the level of fertilization.

As a result of fertilization throughout the study period using different doses in accordance with the experiment protocol, improvements were observed from one year to the next. The yield grew significantly on the fertilized variants compared to the witness lots, as seen in the dry matter content. The best results were obtained in the organic-mineral fertilized variants.

Keeping in mind resource preservation, environment protection and biodiversity conservation, a good strategy regarding these ecological and economic concerns is the use of organic fertilizers on permanent grasslands. Concerning yield growth, the most effective method is the use of mineral and organic-mineral fertilization.

The paper presents the evolution in time of the annual forage production, while data about the floristic composition will be presented in a future paper.
\end{abstract}

Keywords: dry matter, fertilizer, forage production, permanent grassland.

\section{INTRODUCTION}

The latest definition of permanent grassland/ pastures in Romania was included in the Official Monitor № 234 published on the $6^{\text {th }}$ of April 2015, Order № 619 by the Romanian Ministry of Agriculture and Rural Development, where these are known as lands used for grass production or other herbaceous forage plants, in natural (spontaneous) circumstances or through cultivation (seeding), which haven't been included in crop rotation farming for five years or more (Sima, 2015).

The definition of permanent grasslands includes permanent herbaceous and also nonherbaceous pastures which provide essential forage in many extensive livestock systems, especially in more marginal regions. Those systems provide multiple key ecosystem services in some of Europe's most bio-diverse habitats, reducing fire risks, maintaining open landscapes and cultural heritage.

As concerns key global land uses, the world's surface is covered by wide areas of forest (31\%) and permanent meadows and pastures (25.8\%) although regional differences are to be mentioned: forests dominate American and European territories $(40.3 \%$ and $45.4 \%$ of all the land respectively) whereas permanent meadows and pastures cover wide areas in Oceania, Asia and Africa $(44.0 \%, 34.9 \%$ and $30.7 \%$ of all land, respectively).

Permanent grasslands cover $60,840,280$ ha across the EU-28, representing $16 \%$ of the total area. Land covered by pastures is not equally 
distributed among the EU-28. Relevant surfaces of these are found in the United Kingdom (17.92\%), Spain and France (around 14\% each one), Germany (7.65\%) and also Romania (7.41\%) (Osoro, 2014).

Permanent grasslands also occupies a relevant percentage (34.6\%) of the total Utilized Agricultural Area (UAA), with differences between countries: up to $79.7 \%$ of the UAA in Ireland, 64.6\% in United Kingdom, 59.2\% in Slovenia, 50\% in Greece, Luxemburg, Austria and Portugal and around 34\% in Romania (EUROSTAT, 2013).

According to the European Union's Joint Research Centre Peseta II Project, based on the cluster analysis of temperature and precipitation data in 2009, eight agro-climatic zones were defined: Boreal, North Atlantic north, Central Atlantic, North Continental, South Continental, Alpine, North Mediterranean, and South Mediterranean. Romania is part of the southern Continental zone which is the region of "Continental" plant species that grow in cold relatively wet winters and mild dry summers, as well as in cold relatively dry winters and warm dry to occasionally wet summer.

Permanent grasslands have a great diversity in Europe as well as the farming systems linked to them, and can differ between the main agroclimatic zones. Therefore, the practices to improve productivity and efficiency and/or their influence on biodiversity conservation may vary according to that diversity.

The present stage of Romanian agriculture, as far as the size of agricultural and animal exploitations are concerned, impose governmental stimulation measures for the increase of their dimensions (Onaciu et al., 2010), but also measures taken by farmers to improve the quantity and quality of yields.

\section{MATERIALS AND METHODS}

In herbaceous swards the number of species is related to soil $\mathrm{pH}$, humidity and fertility. High fertility levels cause loss of species, except in cases of extreme infertility or acidity, where the reverse is true. Although fertilizer use is most effective in increasing production, it might also cause the greatest loss of diversity. Decisions on sustainable levels of fertilizer use to maintain or enhance the botanical diversity of grassland might be based on knowledge of soil physical and chemical status and past fertility management. A study of
UK upland hay meadows revealed that botanical responses to nutrient applications are driven by whichever macro-nutrient is growth-limiting in the grassland, and by historic nutrient inputs. Therefore the additional application of nutrients for any given meadow should be informed by its soil nutrient status, grass usage, past fertility management and conservation objectives (http:// ec.europa.eu/eip/agriculture/sites/agri-eip).

Considering the above, ways to increase crop yield and quality by applying fertilizers and other amendment work were highlighted by research carried out on damaged permanent grasslands located in different ecological conditions.

Our experiment is set in the northern part of Romania, close to the border with the Ukraine, on a permanent grassland in the environmental conditions of Petrova, Maramureș County. According to the coordinates established in 1933, geographically speaking, Petrova lies at $24^{\circ} 11$ ? 50 east longitude and $47^{\circ} 49^{\prime} 40^{\prime \prime}$ north latitude, $357.74 \mathrm{~m}$ above sea level. The climatic conditions are characterized by mean temperatures of $8.6^{\circ} \mathrm{C}$ and the annual average rainfall is 670.3 $\mathrm{mm}$. Set on a Festuca rubra - Agrostis capillaris (Agrostis tenuis) grassland, at a height of $628 \mathrm{~m}$ and on a $20 \%$ slope, the experiment relied on the randomized blocks method, placed in 4 blocks (rehearsals) with 16 experimental variants. We used a bi-factorial experiment with factor $\mathrm{A}$ as the amendment and factor B as the level of fertilization. The amendment was represented by $6 \mathrm{t} \mathrm{ha}^{-1}$ lime, the organic fertilizer consisting in manure coming from Petrova farm livestock, and the mineral fertilizer was purchased from the Azomures company. The experiment was set up in May 2010 to investigate the influence of organic, organic-mineral and mineral fertilization systems, applied in each year of study, in the autumn, starting with 2012. The amendment was done when the experiment was established.

The first variant V1 is the witness or control, and variants up to V16 - the experimental lots were fertilized in different doses in accordance with the experimental protocol with manure, nitrate and phosphate. V2, V3, V4 are organically fertilized with manure as follows: V2 $\left(\mathrm{N}_{30}-10 \mathrm{t} /\right.$ ha), V3 ( $\left.\mathrm{N}_{100}-33.3 \mathrm{t} / \mathrm{ha}\right), \mathrm{V} 4\left(\mathrm{~N}_{170}-56.6 \mathrm{t} / \mathrm{ha}\right)$. For V5, $\mathrm{V} 6$, and V7, the organic-mineral fertilization based on $\mathrm{N}$ was used as follows: V5 $\left(\mathrm{N}_{30}-5 \mathrm{t} /\right.$ ha manure and $38.8 \mathrm{~kg} /$ ha nitrate), $\mathrm{V} 6\left(\mathrm{~N}_{100}-16.6 \mathrm{t} / \mathrm{ha}\right.$ manure 
and $153.3 \mathrm{~kg} / \mathrm{ha}$ nitrate), V7 $\left(\mathrm{N}_{170}-28.3 \mathrm{t} / \mathrm{ha}\right.$ manure and $266.6 \mathrm{~kg} /$ ha nitrate). For V8, V9, V10 mineral fertilizer based on nitrate was used: V8 $\left(\mathrm{N}_{30}-93.3 \mathrm{~kg} / \mathrm{ha}\right), \mathrm{V} 9\left(\mathrm{~N}_{100}-313.3 \mathrm{~kg} / \mathrm{ha}\right), \mathrm{V} 10\left(\mathrm{~N}_{170}-\right.$ $533.3 \mathrm{~kg} / \mathrm{ha}$ ). V11, V12, V13 were fertilized with mineral nitrate and phosphate-based fertilisers: V11 $\left(\mathrm{N}_{30} \mathrm{P}_{30}-146.6 \mathrm{~kg} /\right.$ ha nitrate and phosphate), V12 $\left(\mathrm{N}_{100} \mathrm{P}_{60}-500 \mathrm{~kg} / \mathrm{ha}\right.$ nitrate and phosphate), V13 $\left(\mathrm{N}_{170} \mathrm{P}_{100}-800 \mathrm{~kg} /\right.$ ha nitrate and phosphate). For V14, V15, V16 organic-mineral fertilization based on $\mathrm{N}$ and $\mathrm{P}$ was used as follows: $\mathrm{V} 14\left(\mathrm{~N}_{30} \mathrm{P}_{30}-\right.$ $5 \mathrm{t} /$ ha manure, $146.6 \mathrm{~kg} /$ ha nitrate and phosphate), V15 $\left(\mathrm{N}_{100} \mathrm{P}_{60}-16.6 \mathrm{t} /\right.$ ha manure, $500 \mathrm{~kg} /$ ha nitrate and phosphate), V16 $\left(\mathrm{N}_{170} \mathrm{P}_{100}-28.3 \mathrm{t} /\right.$ ha manure, $800 \mathrm{~kg} / \mathrm{ha}$ nitrate and phosphate).
Every year there were 2 cuts during the summer, one in June and the other in August so the field was used as hayfield and not for grazing.

\section{RESULTS AND DISCUSSIONS}

Analysing the production of dry matter content, we noticed that in 2012 the total annual average production was $5.7 \mathrm{t} \mathrm{ha}^{-1} \mathrm{DM}, 5.66 \mathrm{t} \mathrm{ha}^{-1}$ DM for the variants with no amendment and 5.78 $\mathrm{t} \mathrm{ha}^{-1} \mathrm{DM}$ for the amendment variants. The annual productions were comprised between $2.93 \mathrm{t} \mathrm{ha}^{-1}$ DM in the control lot, and $7.09 \mathrm{t} \mathrm{ha}^{-1} \mathrm{DM}$ in the fertilization lots with $533.3 \mathrm{~kg} \mathrm{ha}^{-1}$ nitrate N170. This was the highest value along with the one

Tab. 1 The annual DM production ( $\mathrm{t} \mathrm{ha}^{-1}$ ) for all the variants in 2012

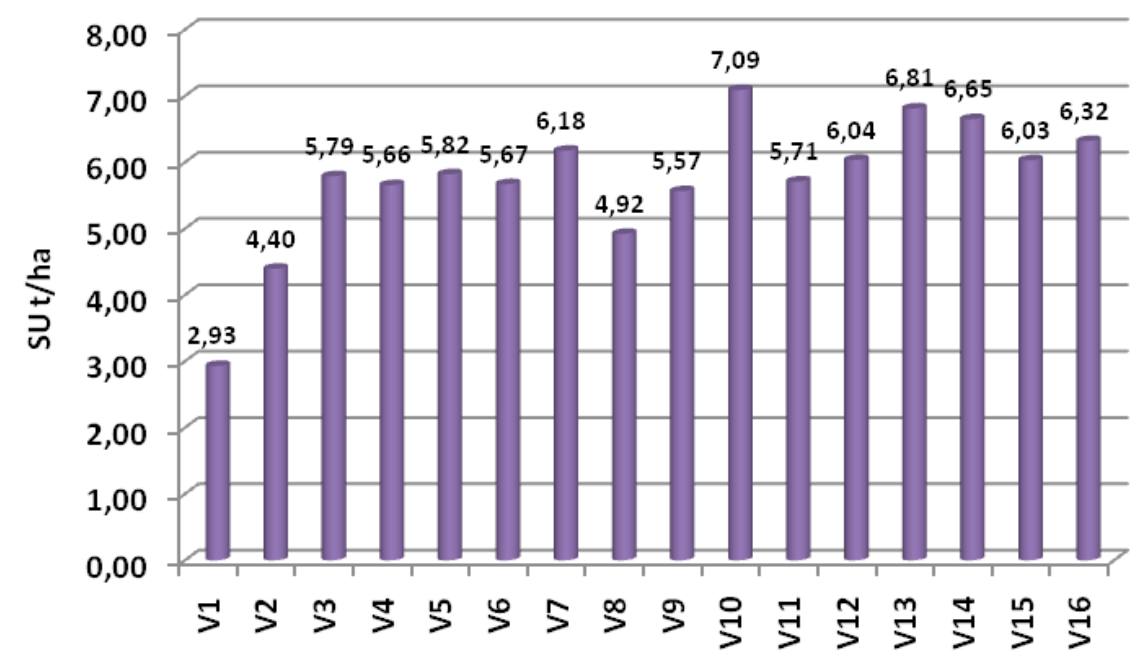

Tab. 2 The annual DM production ( $\mathrm{t} \mathrm{ha}{ }^{-1}$ ) for all the variants in 2013

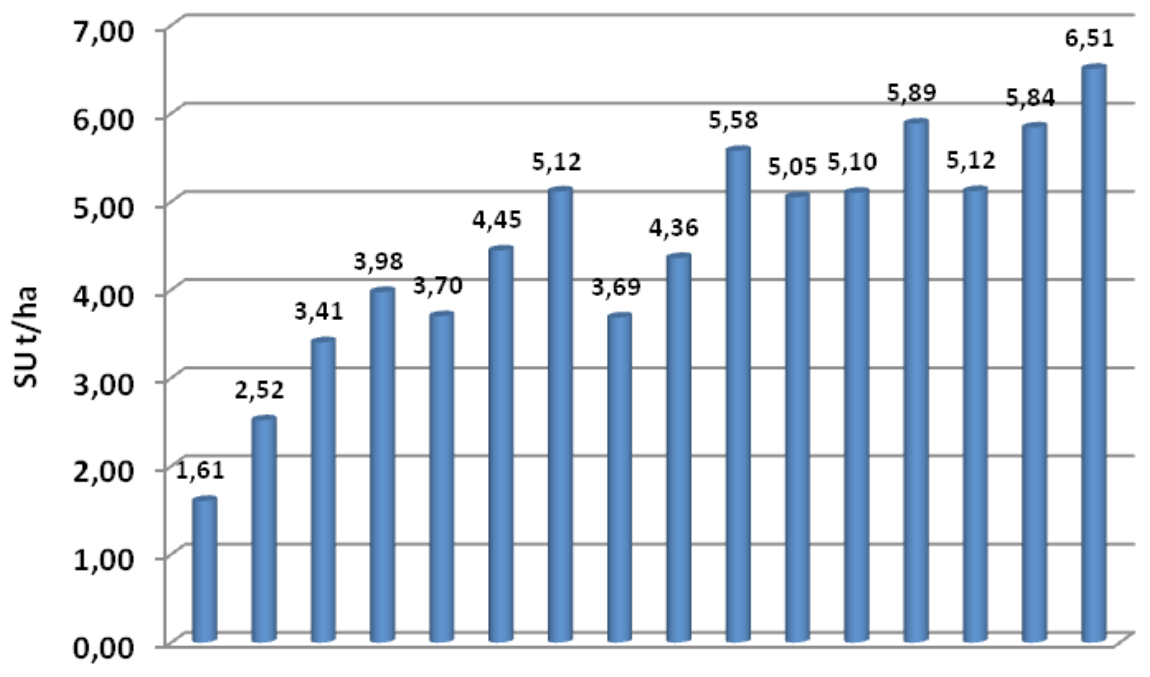


Tab. 3 The annual DM production ( $\left(\mathrm{ha}^{-1}\right)$ for all the variants in 2014

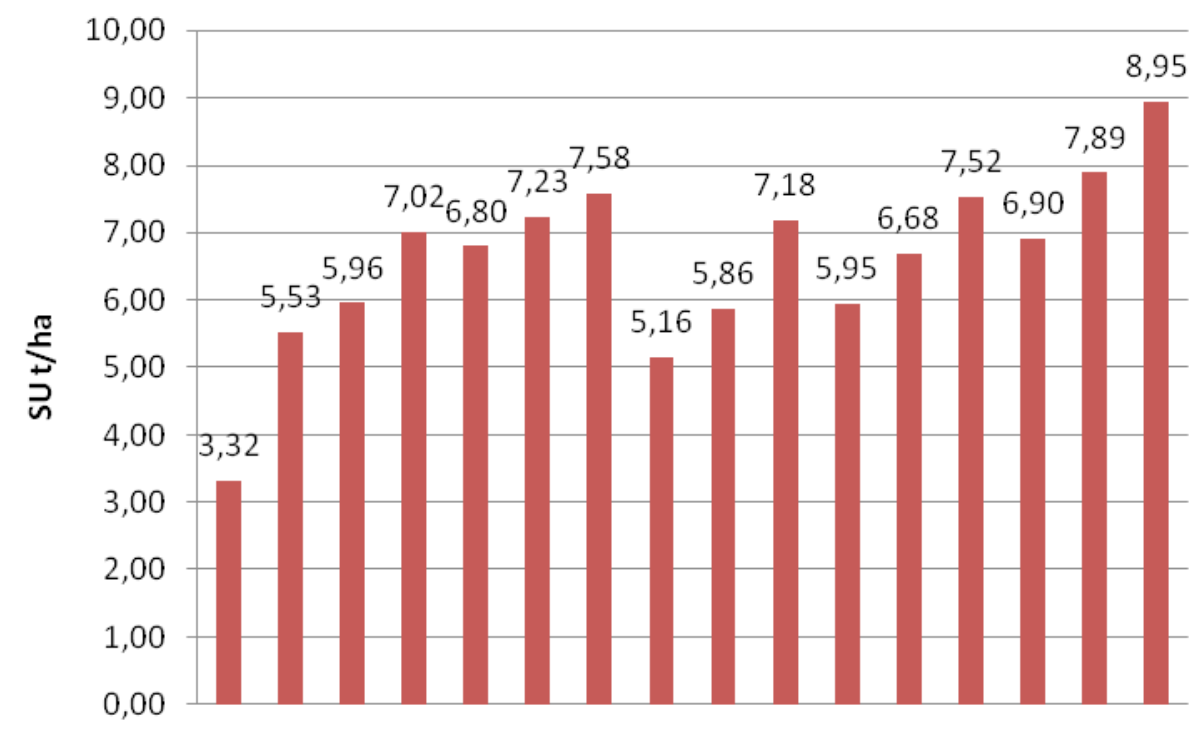

fertilized with $800 \mathrm{~kg} \mathrm{ha}^{-1}$ nitrate and phosphate N170P100, which was $6.81 \mathrm{t} \mathrm{ha}^{-1} \mathrm{DM}$.

Regarding 2013, the total annual average production was $4.49 \mathrm{t} \mathrm{ha}^{-1} \mathrm{DM}, 4.38 \mathrm{t} \mathrm{ha}^{-1} \mathrm{DM}$ for the variants with no amendment and $4.59 \mathrm{t}$ $\mathrm{ha}^{-1} \mathrm{DM}$ for the amendment variants. The annual productions were between $1.6 \mathrm{t} \mathrm{ha}^{-1} \mathrm{DM}$ in the control lot, and $6.5 \mathrm{t} \mathrm{ha}^{-1} \mathrm{DM}$ in the fertilization lots with $800 \mathrm{~kg} \mathrm{ha}^{-1}$ nitrate and phosphate plus $28.3 \mathrm{t} \mathrm{ha}^{-1}$ manure N170P100. These small values were recorded also because of the draught that dominated the experimental area in the spring of 2013 , and which highly affected the vegetation.

The year 2014 was the best year among those studied if we consider the total annual average production, which was $6.59 \mathrm{t} \mathrm{ha}^{-1} \mathrm{DM}, 6.3 \mathrm{t} \mathrm{ha}^{-1}$ DM for the variants with no amendment and 6.7 $\mathrm{t} \mathrm{ha}^{-1} \mathrm{DM}$ for the amendment variants. The annual productions were between $3.2 \mathrm{t} \mathrm{ha}^{-1} \mathrm{DM}$ in the control lot, and $8.95 \mathrm{t} \mathrm{ha}^{-1} \mathrm{DM}$ in the fertilization lots, with $800 \mathrm{~kg} \mathrm{ha}^{-1}$ nitrate and phosphate +28.3 t ha ${ }^{-1}$ manure N170P100.

\section{CONCLUSION}

Fertilization is a good method to improve the quantity and quality of permanent grasslands especially if people use organic, mineral, but also combined fertilizers. Besides direct action on plant nutrition, manure improves the thermal regime of the soil and its aeration, increases its water holding capacity, intensifying the work of soil microorganisms, and mineral fertilizers provide yield growth. Amendments restore degraded soil and have effects on soil microbial properties.

The yield grew significantly on the fertilized variants as compared to the witness lot. This can be seen in the dry matter content. The best results were obtained in the organic-mineral fertilized variants.

Long term fertilization gives best results in time as we can see that the latest year included in the study had the best production values in terms of DM.

As an average over the years, the best production was obtained at the highest level of fertilization with $800 \mathrm{~kg} \mathrm{ha}^{-1}$ nitrate and phosphate plus $28.3 \mathrm{t} \mathrm{ha}^{-1}$ manure N170P100 in V16. Not too far from this variant were the results collected from V13 $\left(\mathrm{N}_{170} \mathrm{P}_{100}-800 \mathrm{~kg} /\right.$ ha nitrate and phosphate) and V10 ( $\mathrm{N}_{170}-533.3 \mathrm{~kg} /$ ha nitrate).

Regarding the organic fertilization, the highest yields were obtained in time in V4 $\left(\mathrm{N}_{170}-56.6 \mathrm{t} / \mathrm{ha}\right.$ manure), but not with significant differences as compared to V3 $\left(\mathrm{N}_{100}-33.3 \mathrm{t} /\right.$ ha manure).

\section{REFERENCES}

1. Onaciu G, Jurco E, Avram A. (2010). Agricultural Potential Characterization in Vegetable and Animal Area in Four Counties from Transylvania. Bulletin UASVM Animal Science and Biotechnologies, 67(1-2): 282-286.

2. Osoro K. (2014). Profitability of Permanent Grassland. May 28, 2014 EIP-AGRI Focus Group: 5-6.

3. Sima N. (2015). Revaluation of permanent grassland. Festuca rubra grasslands from Cindrel Mountains. Ed. Risoprint, Cluj-Napoca - in print. 
4. ${ }^{* * *}$ EUROSTAT (2013). Permanent grassland: number of farms and areas by agricultural size of farm (UAA) and size of permanent grassland area

5. ${ }^{* * *}$ http://appsso.eurostat.ec.europa.eu
6. ${ }^{* * *}$ http://ec.europa.eu/eip/agriculture/sites/agri-eip/ files/fg9_permanent_grassland_profitability _ starting paper_2014_en.pdf 